\title{
Campesinato e sementes crioulas: indícios de decolonialidade
}

\author{
Peasantry and creole seeds: signs of decoloniality
}

\author{
Luciene da Costa Rodrigues ${ }^{1}$ \\ Roberto José Covaia Kosop ${ }^{2}$ \\ José Edmilson Souza-Lima ${ }^{3}$ \\ Valter Roberto Schaffrath ${ }^{4}$
}

\begin{abstract}
Resumo
Os agricultores defendem constantemente uma identidade campesina e tradicional, em contraposição à modernização capitalista. Nesse sentido, há necessidade de apresentar um respaldo teórico para o campo, bem como efetivar o resgate sociocultural dos camponeses. Toma-se, portanto, como objetivo, verificar em que medida as sementes crioulas podem ou não ser caracterizadas como uma manifestação decolonial com intuito de conservar a identidade sociocultural regional, bem como contribuir com o campesinato na construção de um desenvolvimento rural ancorado em princípios agroecológicos. Realizou-se uma revisão bibliográfica de cunho interdisciplinar, a fim de contribuir com a sociobiodiversidade, assim como algumas reflexões teóricas voltadas para as práticas decoloniais, visando à necessidade de conservar as sementes crioulas. A prática de uso e conservação das sementes, por meio do campesinato, é de suma importância para a manutenção da diversidade cultural e de saberes. São sementes que não apresentam modificações genéticas e não utilizam insumos químicos, práticas estas que desempenham importantes funções ambientais e para a saúde humana. Portanto, a conservação das sementes crioulas é um processo de autonomia do sujeito camponês e, consequentemente, está em prol da mantença dos saberes tradicionais ligados às técnicas de produção das heranças regionais brasileiras, ou seja, é um modo de desenvolvimento e aplicação de saberes distintos do padrão dominante de racionalidade.
\end{abstract}

Palavras-chave: Sociobiodiversidade. Agroecossistema. Decolonialidade. Ecocentrismo.

\begin{abstract}
Farmers often advocate for a peasant and traditional identity, in opposition to capitalist modernization; thus, it is necessary providing theoretical support to the field, as well as enabling peasants' sociocultural recovery. Therefore, the aims of the current study are to investigate to what extent creole seeds may, or may not, be characterized as decolonial manifestation in order to preserve the regional sociocultural identity, as well as to enable peasantry to develop rural environments based on agroecological principles. A literature review of interdisciplinary nature was carried out in order to contribute to socio-biodiversity, as well as to some theoretical reflections about decolonial practices focused on conserving creole seeds. Seed use and conservation practices based on peasantry are of utmost importance to maintain cultural diversity and knowledge. Creole seeds do not present genetic modifications and are not subjected to chemical inputs, which are practices that can

\footnotetext{
${ }^{1}$ Bióloga. Mestre em Ambiente e Sistemas de Produção Agrícola (UNEMAT) e doutoranda em Meio Ambiente e Desenvolvimento (UFPR). E-mail: lucycroton@gmail.com

${ }^{2}$ Advogado. Mestre em Direito (UNICURITIBA) e doutorando em Meio Ambiente e Desenvolvimento (UFPR). E-mail: roberto_kosop@hotmail.com

${ }^{3}$ Sociólogo. Mestre em Sociologia Política (UFSC). Doutor em Meio ambiente e Desenvolvimento (PPGMade-UFPR) e docente do a Pós-Graduação em Meio ambiente e Desenvolvimento (PPGMade-UFPR).E-mail: zecaed@ hotmail.com

${ }^{4}$ Agrônomo. Mestre em Agroecossistemas (UFSC). Doutor em Agronomia (UEM) e docente da Pós-Graduação em Meio ambiente e Desenvolvimento (PPGMade-UFPR). E-mail: valter.schaffrath@gmail.com
} 
significantly affect the environment and human health. Therefore, the conservation of creole seeds is a peasant-autonomy process and, consequently, it favors the maintenance of traditional knowledge in association with techniques focused on producing Brazilian regional inheritance. In other words, it is the way to develop and apply knowledge different from that linked to dominant rationality standards. Keywords: Socio-biodiversity. Agroecosystem. Decoloniality. Ecocentrism.

\section{Introdução}

O sucesso da agricultura se deve à domesticação de sementes realizada pelos homens modernos, há cerca de 10.500 anos numa área conhecida como Crescente Fértil do Mediterrâneo oriental (atualmente Líbano, Síria, Turquia, Irã, Jordânia e Israel). Nessa região, a cevada (Hordeum vulgare) e o trigo (Triticum sp.) foram, aparentemente, as primeiras plantas a serem cultivadas, com a lentilha (Lens culinaris) e a ervilha (Pisum sativum) vindo logo em seguida (RAVEN et al., 2007). Dessa forma, considera-se que a interação do ser humano na natureza, a partir da domesticação de sementes, se apresenta como essencial para o surgimento de novas espécies tais como a Triticale (Triticum secale) e a Nectarina (Prunus persica) e outras variedades de plantas, manejadas pelo homem.

A agricultura, desde os seus primórdios até os dias atuais, passou por diversas transformações, acompanhando a evolução das sociedades. Atualmente, dois modelos de agricultura são discutidos mundialmente, uma oriunda da Revolução Verde (denominada de Agricultura Industrial ou Convencional), baseada no pacote tecnológico (fundamentada em três pilares, a saber: agroquímicos, motomecanização e manipulação genética), e outro Camponês, baseado no conhecimento empírico (agricultura de base ecológica). O modelo da Agricultura Industrial vem sendo difundido no campo desde o século XX, se acentuando após a Revolução Verde na década de 60, no Brasil. As transformações provocadas por este modelo de desenvolvimento rural contradizem toda a história da agricultura construída até então, e não valorizam os saberes locais que se apoiam nos conhecimentos acumulados ao longo de várias gerações pelo campesinato (PINHEIRO et al., 2000).

O modelo de produção agrícola baseado no uso do pacote tecnológico, como insumos químicos, sementes modificadas geneticamente, nenhuma diversidade de cultivos, máquinas agrícolas, monoculturas, bem como a concentração de terras em grandes latifúndios. Entre os inúmeros problemas causados por este modelo, destaca-se perda da biodiversidade local, sob consequências que vão desde a erosão genética dos recursos naturais até a mais drástica, como a insegurança alimentar e a dependência das sementes melhoradas oriundo da Revolução Verde (DOMINGUEZ et al., 2000; AMORIM, 2016). 
Opondo-se ao agronegócio, o outro jeito de se fazer agricultura é protagonizado pela agricultura camponesa, cujas práxis produtivas altamente integradas com a natureza podem ser consideradas guardiãs da biodiversidade, mesmo diante do contexto histórico atual, no qual as classes dominantes e a privatização dos saberes impõem a artificialização da agricultura (CARVALHO, 2012). Dessa forma, alguns camponeses têm conseguido reinventar suas práticas e se reproduzir socialmente, passando adiante uma concepção de mundo que afirma a autonomia da agricultura contemporânea perante o agronegócio, e que corrobora para a construção da Agroecologia e de uma relação que se deseja mais próxima da convivência entre sociedade-natureza.

Diante do exposto, a Agroecologia se configura como uma nova abordagem científica que integra os princípios agronômicos, ecológicos, socioeconômicos e culturais à compreensão e avaliação do efeito de tecnologias sobre os sistemas agrícolas e a sociedade como um todo (ALTIERI, 2004). Dessa forma, o saber agroecológico é fator elementar na construção de um novo paradigma produtivo, uma vez que mostra a possibilidade da produção de alimentos respeitando o ambiente (LEFF, 2002).

Um dos elementos abordados pela Agroecologia é o manejo e a conservação das sementes crioulas $^{5}$, que surgem como produtos da prática da agrobioversidade, e que representa uma simbologia importante na compreensão dos desafios para a construção do paradigma agroecológico. As variedades crioulas são aquelas que passaram por processos de melhoramento tradicional, sendo manejadas pelos camponeses e/ou povos tradicionais (quilombolas, ribeirinhos, indígenas entre outros) por meio de uma seleção dirigida e adaptada às condições ambientais locais (JARVIS et al., 2000; GLIESSMAN, 2007).

Nos últimos anos, tem-se dado atenção ao campesinato e às populações tradicionais como mantenedoras da diversidade biológica natural (CUNHA et al., 2015), em função de suas práticas agrícolas, mas também como guardiãs da variabilidade e biodiversidade das plantas cultivadas e do conhecimento associado a toda essa riqueza. Nesse sentido, o presente artigo tem como objetivo verificar em que medida as sementes crioulas podem ou não ser caracterizadas como uma manifestação decolonial com intuito de conservar a manifestação sociocultural regional, bem como

\footnotetext{
${ }^{5}$ Segundo a Lei $\mathrm{n}^{\mathrm{o}} 10.711$ de agosto de 2003, conhecida como Lei das Sementes (BRASIL, 2003), descreve a mesma como "variedade desenvolvida, adaptada ou produzida por agricultores familiares, assentados da reforma agrária ou indígenas, com características fenotípicas bem determinadas e reconhecidas pelas respectivas comunidades e que, a critério são considerados também os descritores socioculturais e ambientais, não se caracterizem como substancialmente semelhantes às cultivares comercial". Estas variedades, que detêm a maior variabilidade dentre as plantas cultivadas, são mantidas em grande parte por meio de bancos de sementes de agricultores, principalmente, nos países em desenvolvimento.
} 
contribuir com o campesinato na construção de um desenvolvimento rural ancorado em princípios agroecológicos.

Visando um novo direcionamento para os ideais de desenvolvimento, sustentabilidade e dignidade, o bem-estar das gerações presentes e da relação destas com a natureza, se verificará fundamental para a conscientização ambiental fundada em uma epistemologia que se preocupe com as interrelações entre homem e natureza. Buscar-se-á, sob um aporte decolonial que evidencie um rompimento com a colonialidade da natureza, identificar a divisão binária, de origem cartesiana, entre natureza e ser humano.

Para tanto, abordar-se-á a Agroecologia, sua história, o papel do campesinato na conservação e no manejo das sementes crioulas e estas propriamente ditas. Consequentemente, aproximar-se-á o pensamento decolonial como forma de enaltecer a prática deste manejo como um patrimônio a ser protegido e, finalmente, as vantagens na utilização das sementes crioulas, bem como, propor o fortalecimento de seu uso agroecológico.

Nesse contexto, diante de diversas intenções legislativas e movimentos universalizantes da agricultura, este estudo tem por intuito trazer fundamentos epistemológicos e práticos que ajudam a identificar vínculos entre a agricultura camponesa e o pensamento decolonial, por intermédio das práticas de uso, manejo e conservação das sementes crioulas. Com base em revisão bibliográfica e em algumas reflexões teóricas, a pesquisa visa proporcionar uma abordagem interdisciplinar e contribuir com a sociobiodiversidade brasileira e com fundamentos hábeis que possibilitem proteger o direito dos camponeses visando contribuir com as políticas públicas e com a diversidade biológica e cultural.

\section{Papel da Agroecologia na conservação de saberes}

A ciência agroecológica busca integrar os saberes históricos dos camponeses com os conhecimentos de diferentes ciências, permitindo tanto a compreensão, análise e crítica do atual modelo do desenvolvimento e de agricultura, como o estabelecimento de novas estratégias para o desenvolvimento rural e novos desenhos de agriculturas mais sustentáveis, desde uma abordagem interdisciplinar e holística (VIGLIZZO, 2001).

Como afirmam Guzmán e Ottmann (2004), os elementos centrais da Agroecologia podem ser agrupados em três dimensões: - ecológica e técnico-agronômica; - socioeconômica e cultural; e sociopolítica. Estas dimensões não são isoladas. Estas se entrecruzam, influem uma à outra, de modo que estudá-las, entendê-las e propor alternativas supõe, necessariamente, uma abordagem inter, multi 
e transdisciplinar, razão pela qual os agroecólogos e seus pares lançam mão de ensinamentos de diferentes áreas do conhecimento, caracterizando-a como uma ciência da complexidade, não se enquadrando no campo do paradigma convencional, cartesiano.

Segundo Norgaard (1989) as bases epistemológicas da Agroecologia mostram que, historicamente, a evolução da cultura humana pode ser explicada com referência ao meio ambiente, ao mesmo tempo em que a evolução do meio ambiente pode ser explicada com referência à cultura humana. Ou seja: os sistemas biológicos e sociais têm potencial agrícola; este potencial foi captado pelos agricultores tradicionais por meio de um processo de tentativa, erro, aprendizado seletivo e cultural; os sistemas sociais e biológicos coevoluíram de tal maneira que a sustentação de cada um depende estruturalmente do outro; a natureza do potencial dos sistemas social e biológico pode ser melhor compreendida dado o nosso presente estado do conhecimento formal, social e biológico, estudando-se como as culturas tradicionais captaram este potencial e o desenvolvimento agrícola, por meio da Agroecologia, manterá mais opções culturais e biológicas para o futuro e produzirá menor deterioração cultural, biológica e ambiental que os enfoques das ciências convencionais por si sós.

Nesse contexto, a Agroecologia é entendida como um enfoque científico destinado a apoiar a transição dos atuais modelos de desenvolvimento rural e de agricultura industrial para estilos de desenvolvimento rural e de agriculturas mais sustentáveis (CAPORAL; COSTABEBER, 2000a; 2000b; 2001; 2002). Segundo Altieri (1992; 1994; 1995; 2001) essa ciência constitui um enfoque teórico e metodológico que, lançando mão de diversas disciplinas científicas, pretende estudar a atividade agrária sob uma perspectiva ecológica.

Sendo assim, a Agroecologia, a partir de um enfoque sistêmico, adota o agroecossistema ${ }^{6}$ como unidade fundamental de análise, tendo como objetivo proporcionar as bases científicas (princípios, conceitos e metodologias) necessárias para a construção de agriculturas de bases ecológicas, visando a sustentabilidade multidimensional. Logo, mais do que uma disciplina específica, a Agroecologia se constitui num campo de conhecimento que reúne várias "reflexões teóricas e avanços científicos, oriundos de distintas disciplinas" que têm contribuído para conformar o seu atual corpus teórico e metodológico (GUZMÁN CASADO et al., 2000 p. 81). Por outro lado,

\footnotetext{
${ }^{6}$ Agroecossistema é a unidade fundamental de estudo, nos quais os ciclos minerais, as transformações energéticas, os processos biológicos e as relações socioeconômicas são vistas e analisadas em seu conjunto. Sob o ponto de vista da pesquisa agroecológica, seus objetivos não são a maximização da produção de uma atividade particular, mas a otimização do agroecossistema como um todo, o que significa a necessidade de uma maior ênfase no conhecimento, na análise e na interpretação das complexas relações existentes entre as pessoas, os cultivos, o solo, a água e os animais (ALTIERI, 2002).
} 
como nos ensina Gliessman (2007), o enfoque agroecológico pode ser definido como a aplicação dos princípios e conceitos da Ecologia no manejo e desenho de agroecossistemas mais sustentáveis.

Segundo Gliessman (2007), as agriculturas mais sustentáveis, sob o ponto de vista agroecológico, são aquelas que, tendo como base uma compreensão holística dos agroecossistemas, sejam capazes de atender, de maneira integrada, critérios como baixa dependência de inputs comerciais; uso de recursos renováveis localmente acessíveis; utilização dos impactos positivos ou negativos do ambiente; manutenção a longo prazo da capacidade produtiva; preservação da diversidade biológica e cultural; utilização do conhecimento e da cultura da população local e produção de mercadorias para o consumo interno antes de produzir para a exportação (GLIESSMAN, 2007).

Para Altieri (2002), a expressão agricultura sustentável se refere à “( ...) busca de rendimentos duráveis a longo prazo por meio do uso de tecnologias de manejo ecologicamente adequadas”, o que requer a “(...) otimização do sistema como um todo e não apenas o rendimento máximo de um produto específico". A opção pela terminologia "agricultura de base ecológica" que temos utilizado, tem a intenção de distinguir os estilos de agricultura resultantes da aplicação dos princípios e conceitos da Agroecologia.

Nesse contexto, agriculturas mais sustentáveis não se referem apenas à substituição de insumos químicos e práticas depredadoras de recursos naturais. Trata-se da necessidade de caminhar em direção ao redesenho dos agroecossistemas segundo princípios ecológicos e inúmeras variáveis sociais, culturais e políticas. É por esta razão que na Agroecologia não existem pacotes, nem modelos. A aplicação do enfoque agroecológico pode levar a tantos tipos de agriculturas quantos forem os arranjos possíveis entre as condições de cada agroecossistema e os sistemas culturais dos camponeses envolvidos.

Uma das inovações determinantes da Agroecologia é o reconhecimento da existência de racionalidades ecológicas nos modos camponeses de produção. Essas racionalidades expressam estratégias de produção econômica e reprodução socioambiental, resultantes da capacidade do campesinato de ajustar seus meios de vida aos ecossistemas em que vivem e produzem. Esse reconhecimento da importância dos saberes locais e da capacidade do camponês de gerar novidades trazem para a Agroecologia implicações epistemológicas de largo alcance, uma vez que seu desenvolvimento como abordagem científica nega o positivismo lógico que descarta todo e qualquer conhecimento que não seja validado pelo método científico convencional cartesiano (PETERSEN et al., 2009). 
Nesse processo de construção de uma nova perspectiva científica, a própria organização do campesinato desempenha importantes funções na dinamização de redes sociotécnicas capazes de mobilizar os camponeses em torno aos processos de inovação agroecológica. Nessa ótica, o camponês desenvolve papel fundamental quando os assuntos são: agricultura de base ecológica e prestação de serviços ambientais (DENARDI, 2001). A interação de ambos associados a princípios agroecológicos desempenham caminhos alternativos para uma agricultura sustentável, salientando o foco nas dimensões econômicas, sociais e ambientais.

Nesse contexto, Toscano (2003) apresenta que o bom desempenho e o fortalecimento dos camponeses estão na dependência da capacidade de articulação dos diversos atores sociais envolvidos e comprometidos com o campesinato, por fim, enquadra-se nesse assunto a organização dos camponeses com vista ao resgate das formas de cultivo e como guardiões de sementes crioulas ${ }^{7}$ a caminho de um desenvolvimento rural sustentável.

Logo, guardiões são aqueles camponeses que possuem e mantêm por processo de multiplicação ao longo do tempo sementes crioulas de diferentes espécies (BEVILAQUA et al. 2009). O enfoque não precisa ser necessariamente apenas conservacionista, mas também de seleção das plantas mais adaptadas aos sistemas de produção local. Como característica dos guardiões de sementes está o reconhecimento do seu papel pela localidade ou por meio da análise de evidências apresentadas.

Os camponeses e suas entidades representativas são responsáveis pela manutenção de um patrimônio genético para a humanidade, por meio da conservação das sementes de cultivares crioulas (PELWING et al., 2008) assim como os povos tradicionais, como os quilombolas, ribeirinhos, indígenas, entre outros. Os guardiões desenvolvem técnicas empíricas de cunho sociocultural para resgatar, manter e dispersar as sementes crioulas, cujas práticas e conhecimento são passadas de geração em geração.

Para Bevilaqua et al. (2014), “(...) a conservação das sementes de variedades crioulas tornouse um aspecto fundamental na preservação da biodiversidade”. Por se entender que sementes crioulas não remete apenas as sementes, mas também a fauna, a flora, a sua conservação e a produção, não representa somente a manutenção das variedades de sementes existentes, mas a garantia de preservação do ambiente, e consequentemente, de outros seres vivos que nele habitam. Práticas como o manejo das sementes crioulas evidenciam o caráter multidimensional da sustentabilidade (SACHS,

\footnotetext{
${ }^{7}$ Sementes crioulas são variedades locais, produzidas e conservadas por agricultores familiares, assentados da reforma agrária e povos e comunidades tradicionais, destacando-se o trabalho das mulheres nesse processo (PLANO NACIONAL DE AGROECOLOGIA E PRODUÇÃO ORGÂNICA-PLANAPO, 2013).
} 
1994), atingindo, ainda que por pequena escala, um desenvolvimento cultural, espacial, ecológico, social e econômico.

Assim, tem-se a intenção de pensar um desenvolvimento aplicado à participação do campesinato para o planejamento contínuo da ocupação do espaço, do processo de crescimento e das práticas agroecológicas inerentes ao âmbito rural.

\section{Prática e patrimônio decoloniais}

O fundamento de um progresso polarizado colabora para a perpetuação de modelos e práticas hegemônicas que subalternizam saberes tido como subdesenvolvidos. Desta forma, “[...] a degradação ambiental e o avanço da pobreza tornaram-se os sinais claros da crise social do nosso tempo" (LEFF, 1995, p. 125).

A partir de um olhar colonial, a humanidade estaria dividida em espécies e subespécies (QUIJANO, 2005), devendo ocorrer uma hierarquização para diferenciar e separar os homens, diante suas particularidades, por intermédio de instrumentos legais que permitam o distanciamento entre seres estranhos.

O processo de colonização induz a um distanciamento da realidade ao adotar uma identidade universal que não reflete os anseios contemporâneos brasileiros. O domínio colonial marca a história latino-americana não só no intuito de transformar a realidade, como também a maneira de contá-la. Sob uma ótica eurocêntrica ${ }^{8}$, a modernidade seria um processo emancipatório da imaturidade a partir de um esforço racional que proporcionaria um novo desenvolvimento a ser imposto à humanidade.

A espoliação epistemológica legitimou as diferenças entre o ser colonizador e aquele objeto de colonização. Diversas noções de raça e cultura operaram para gerar identidades opostas que possibilitassem a justificação de um poder racional por parte do colonizador.

A colonialidade de poderes, como um fator constitutivo da realidade moderna liberal é fundada a partir de uma ciência que considera o espaço/tempo dicotômico, colocando o continente europeu como ponto de partida para o crescimento dos saberes. Possível afirmar que “(...) a colonialidade é constitutiva da modernidade" (MIGNOLO, 2005, p. 44).

O processo de descobrimento do continente americano e do indivíduo que ali se encontrava, instaurou uma assertiva de conhecimento do Outro não para entendê-lo, mas sim, para dominá-lo. “A

\footnotetext{
8 Tratando-se de uma perspectiva crítica do eurocentrismo, importante salientar que não se refere a todos os modos de conhecimento europeus, “(...) mas a uma específica racionalidade ou perspectiva de conhecimento que se torna mundialmente hegemônica colonizando e sobrepondo-se a todas as demais, prévias ou diferentes, e a seus respectivos saberes concretos, tanto na Europa como no resto do mundo" (QUIJANO, 2005, p. 115).
} 
relação básica entre os centros e as periferias foi o saque a exploração, tanto da mão de obra, indígena e posteriormente africana, como também de recursos naturais” (COLAÇO, 2012, p. 127). Possível afirmar que, como paradigma eurocêntrico, a modernidade se tem compreendida no final do século XV e com a conquista do continente americano e do oceano Atlântico. Portanto, “(...) a América Latina entra na Modernidade (muito antes que a América do Norte) como a outra face: dominada, explorada, encoberta" (DUSSEL, 2005, p. 28)

Reconhecer o ocultamento das dimensões particulares por questionamentos globais nos mais versos campos das ciências sociais é uma dificuldade para que sejam possibilitadas formular alternativas ao discurso hegemônico. Não há, portanto, como negar o vínculo entre a modernidade imposta e o movimento colonial. "Impregnadas desde suas origens por um imaginário eurocêntrico, as ciências sociais projetaram a ideia de uma Europa ascética e autogerada, formada historicamente sem contato algum com outras culturas" (CASTRO-GÓMEZ, 2005, p. 83).

No mesmo viés, há a construção de uma imagem silenciadora dos discursos regionais, consolidando uma autoimagem de poder. Ou seja, "A pós-modernidade autoconcebida na linha unilateral da história do mundo moderno, continua ocultando a colonialidade e mantém a lógica universal e monolítica" (MIGNOLO, 2005, p. 34).

O discurso decolonial ${ }^{9}$ e a ecologia dos saberes ${ }^{10}$ vêm na esteira de ressignificar os conceitos da produção de conhecimento eurocêntrica e refundar as bases epistemológicas no intuito de aproximar o discurso agroecológico de uma eficácia material. Portanto, as representações modernas de desenvolvimento (e alternativas a este) reforçam as tendências de fuga da hierarquia colonial que estabelece uma diferença entre o saber válido da doxa do outro.

O mundo colonial deixa de perceber as conflitivas e variadas manifestações econômicas, sociais, jurídicas e políticas que transformam as estruturas sociais de uma determinada região. "A imagem hegemônica não é, portanto, equivalente a estruturação social, e sim a maneira pela qual um grupo, o que impõe a imagem, concebe a estruturação social” (MIGNOLO, 2005, p. 43). As relações de poder se tornam assimétricas e a participação ativa das diferenças é reduzida, justificando as intenções decoloniais que rompem com tendências hegemônicas do poder.

\footnotetext{
9 As experiências da modernidade não europeias não mais podem permanecer escondidas ou ignoradas. Tendo como fundamento o pensamento decolonial (MARTINS, 2014), há a aproximação de um movimento crítico que rompe com o processo colonizador, propondo, assim, uma desconstrução de movimentos unitários, em prol da diversidade dos saberes emergentes que estejam associados com a verdadeira realidade social Latino-americana.

${ }^{10}$ A ecologia dos saberes é “(...) fundamentada na ideia da diversidade epistemológica do mundo, no reconhecimento da existência de uma pluralidade de formas de conhecimento além do conhecimento científico. Isso implica renunciar a qualquer epistemologia geral (PORTANOVA; CORTE, 2015, p. 136)
} 
Tal dicotomia permitiu que houvesse uma crise na epistemologia ambiental complexa que determinou sujeitos tecnicistas e destrutivos com epistemes diferentes da eurocêntrica. "Ao tornar-se técnico, o conhecimento descarta a possibilidade de se conhecer desinteressadamente, pelo prazer de conhecer e de se buscar o desconhecido" (FLORIANI; KNECHTEL, 2003, p. 43). Neste aspecto, a natureza é tida como um ser estranho e distante da vida humana, mediada por instrumentos artificiais pela sociedade.

As expressões culturais dos dominados, igualmente, são extirpadas e ocultadas, uma vez que o caráter universal dos conhecimentos eurocêntricos tende a negar aquele Outro que não corresponda com as manifestações de poder hegemônico (FOUCAULT, 2011) que fundamentam o campo epistemológico. As manifestações da colonização compelem que os dominados se questionem, constantemente, acerca da realidade que lhe norteia.

A partir de tanto, entende-se que "(...) o subdesenvolvimento latino-americano não é uma etapa no caminho do desenvolvimento, mas sim uma contrapartida ao desenvolvimento alheio" (GALEANO, 1983, p. 264). Tal consideração leva a cabo o pensamento eurocêntrico que construiu sujeitos de intervenção nas práticas contemporâneas de desenvolvimento que legitimaram processos de exclusão, social, epistêmica, econômica e política.

Este saber ainda tenta inviabilizar os novos projetos hermenêuticos, vez que o desenvolvimento, unicamente, econômico “(...) torna-se parte de um processo de legitimação mais efetivo para a homogeneização do mundo e da erosão de sua riqueza ecológica e cultural" (SHIVA, 2003, p. 81). Desta forma, não se pode requerer de sujeitos subalternizados um pensar original acerca do desenvolvimento, a partir de valores tradicionais eurocêntricos que se encontram desassociados da realidade inerente às próprias mãos.

A crise ambiental suscita a necessidade de rever as relações do homem com a natureza e, em particular, a racionalidade produtiva por meio da qual se articulam os processos ecológicos que produzem recursos naturais e os processos tecnológicos de transformação industrial (LEFF, 1995, p. 127).

Por um conceito de desenvolvimento moderno que agregue uma nova visão da dignidade ampliada, as particularidades culturais são levadas em consideração para determinar questões de eficácia, rendimento e sustentabilidade multidimensional. "A compreensão das características e do conceito ampliado de desenvolvimento facilita a elaboração e implementação de um plano de desenvolvimento das regiões" (OLIVEIRA, 2002, p. 38).

Este giro posiciona o hermeneuta na posição de empreender novas atitudes que possam erradicar a pobreza e fundamentar uma episteme, eminentemente, regional. "Os novos direitos 
emergem do grito da natureza e das lutas sociais que reivindicam as formas culturais do ser humano" (LEFF, 2012, p. 349). Expressando um discurso de sustentabilidade amplo, propõe-se uma ressignificação dos sentidos existenciais e, consequentemente, do campo agroecológico.

Além do propósito da conservação da natureza, os direitos ambientais se encaminham a recuperar e revalorizar as relações entre cultura e natureza, a reabrir as diversas vias de outridade e a multiplicar as heterogêneas formas de vida que permaneceram reduzidas e truncadas pelo processo de homogeneização do mundo moderno, balizado pela racionalidade instrumental, econômica e jurídica que se foi impondo sobre o destino dos povos e da natureza (LEFF, 2012, p. 352).

Sob tal ótica, “[...] os saberes locais não são mais considerados inferiores em relação ao conhecimento científico ocidental, mas visam questionar a ideia de que há saberes universais válidos para todo o planeta" (COLAÇO, 2012, p. 171). O debate é direcionado por estratégias conceituais que apontam limites às proposituras homogêneas e àquelas que legitimam um valor aos projetos eurocêntricos.

A emergência de saberes que dão conta das relações de sujeitos entre si e destes com a natureza, em especial no fomento de uma vida digna, determina o espaço para que a decolonização surja para viabilizar este giro cultural.

Porém, não se tratava de apenas destacar a importância da cultura como categoria analítica para delinear e avaliar os programas de desenvolvimento, mas também de outorgar uma maior participação a esses sujeitos na execução dos programas de desenvolvimento (BUENAVENTURA, 2008, p. 276).

Esta produção importa num discurso de desenvolvimento que entenda a solidariedade e o compartilhamento como fundamentos para a evolução epistêmica, permitindo articular um entrelaçado constitucional e institucional que gere modelos teóricos hábeis a canalizar um processo dialógico de mudanças sociais.

Em prol de uma nova direção para os ideais de desenvolvimento, sustentabilidade e dignidade, o bem-estar das gerações presentes e da relação destas com a natureza é fundamental para o fomento de uma consciência ambiental que se preocupa com os sujeitos (homem e natureza) e com a geração de capital.

Designando subjetividades e saberes pluriversais, a decolonialidade proporciona respostas para os objetos e seres colonizados. Logo, correto afirmar que "[...] significa um tipo de atividade (pensamento, giro, opção) de enfrentamento à retórica da modernidade e à lógica da colonialidade" (GROSFOGUEL; MIGNOLO, 2008, p. 34). 
Busca-se, por esses fundamentos e mediante um rompimento com a colonialidade da natureza, evidenciar a divisão binária, de origem cartesiana, entre natureza e ser humano, ação esta que ampliou o espaço entre o sujeito Homem e o objeto Ambiente e rompeu com a relação criada pelos povos originários dos continentes latino-americano e africano.

\begin{abstract}
A economia de mercado pode ser viável desde que não marginalizasse a diversidade cultural e impusesse unilateralmente o monopólio da produção e do consumo sobre todas as esferas da vida humana e da natureza. Bastasse para isso que se instaurasse a convivência de culturas e civilizações, que se valorizassem as longas e profundas experiências dos saberes camponeses, de formas de vida e de experiências multiculturais, que se privilegiasse a ética da sustentabilidade, contrária aos diversos extermínios instituídos pela modernidade: o extermínio das culturas humanas estranhas às lógicas de mercado, da biodiversidade, das florestas, dos rios, dos recursos naturais não renováveis (FLORIANI; KNECHTEL, 2003, p. 44).
\end{abstract}

Neste viés, entende-se que a visão metódica de uma prática, visando unicamente o desenvolvimento econômico, cria um cenário de destruição, pois acredita-se que recursos naturais são infinitos, os utilizando de forma descompensada (SANTOS, 2006). A biodiversidade considerada somente como matéria-prima é tida como algo a ser transformado e domado, imperando um caos nos processos rurais ao colocar em risco a diversidade cultural e práticas regionais que integram diretamente e de forma diversa à hegemônica com o ambiente.

A análise decolonial, portanto, procura, dentre vários outros objetivos, romper com as falsas percepções de que a sociedade eurocêntrica moderna é superior e que suas práticas agrícolas mais eficientes, sob todos os aspectos, às regionais latino-americanas, que todos os processos científicos validados são originários de grupos elitizados e que o marginalizado tem culpa ao se opor à subalternização.

Tal transformação radical implica na alteração dos conceitos de ambiente, desenvolvimento e dignidade, expressando uma grande quebra paradigmática no sentido de legitimar novas manifestações discursivas no campo das práticas agroecológicas. Dentro desta nova realidade, observa-se uma transição para um tipo de pensamento mais aberto e disposto a compreender as produções locais, sejam elas epistemológicas e/ou técnicas. Assim, a preservação dos patrimônios culturais, a partir da década de 60 (CHOAY, 2001), vem ganhando maior força ao valorizar bens antes não consagrados.

Grupos engajados socialmente, tais como os camponeses, lembram da importância agroecológica do manejo das sementes crioulas, fato este que significa muito em termos simbólicos e, da mesma forma, emerge como uma ação de sentido decolonial, pois colabora, por uma perspectiva regional, para a construção da civilização multidimensional brasileira. 
Pensar em alternativas no âmbito rural se faz uma necessidade, vide que a contínua degradação ambiental nestas zonas não atinge tanta visibilidade quanto os centros urbanos (MARTÍNEZ, 2009). Nos processos de reprodução constante é evidente a marginalização de todo o universo simbólico e cultural próprios de membros subjugados, e a única manifestação digna de ser reproduzida é aquela hegemônica e silenciadora das demais no arbitrário cultural.

Não somente o universo simbólico, mas também as práticas agroecológicas destes são igualmente marginalizados, motivo pelo qual, merecem o reconhecimento como patrimônio decolonial frente a práticas que trazem maiores mazelas ao ambiente socionatural.

Consequentemente, em um modelo de desenvolvimento que reúna práticas regionais, o paradigma, desde às margens, tem como fundamento, o exercício total das potencialidades da coletividade local. Para tanto, se fazem necessários:

[...] critérios alternativos de destinação de fatores, substituindo o princípio da máxima rentabilidade, pelo de mobilização integral de recursos; critérios alternativos de intercâmbio de produtos, substituindo o princípio predominante de vantagens comparativas, pelo de benefícios obtidos pelo comércio; formas específicas de organização social e econômica (desenvolvimento rural e de aldeias, uso de tecnologias intensivas em mão-de-obra por meio de projetos pequenos e medianos) com destaque para a organização territorial e; uma transformação no conceito de desenvolvimento, que abranja metas sociais mais amplas, com uma motivação endógena (LIMA ANDRADE, 1996, p. 19-20 apud OLIVEIRA; SOUZA-LIMA, 2006).

Em um contexto de construção do campo agroecológico no qual o único caminho é imposto pelo capital por meio de uma agricultura dominada pelas grandes empresas, o manejo das sementes crioulas por camponeses são exemplos de patrimônio decolonial que deve ser defendido por uma racionalidade inclusiva e dialógica, ao invés de projetos legislativos que possam trazer um retrocesso ao âmbito agroecológico ${ }^{11}$.

Logo, a agroecologia representa uma construção que confronta a agricultura industrial que, ainda, é o modelo hegemônico, embora integre a crise do capitalismo em diversos países. Pela decolonialidade, se fundamenta um modo de agricultura campesina que seja produtivo e, ao mesmo

\footnotetext{
${ }^{11}$ O Projeto de Lei número 827/2015, atualmente em trâmite na Câmara dos Deputados tem como objetivo ampliar os direitos de propriedade das grandes empresas internacionais de sementes e insumos sobre as variedades vegetais que desenvolvem em laboratórios. Desta forma, restringiria o direito de agricultores em conservar, trocar ou vender livremente as sementes. Neste mesmo viés retrógrado, pode-se salientar o Projeto de Lei número 1117/2015, no qual pretende modificar a Lei de Biossegurança para permitir a utilização das tecnologias genéricas de restrição de uso (desenvolve as sementes terminator ou suicidas) para a produção de sementes estéreis nos casos de plantas biorreatoras, de produção vegetativa e quando o uso das sementes estéreis for uma medida de segurança à atividade desenvolvida. Portanto, vê-se que o presente clamor decolonial tende a ir contra movimentos que restrinjam o direito de muitos para proteger o direito de poucos, normalmente, daqueles que detém o poder econômico e político.
} 
tempo, ecologicamente equilibrado, conservando a biodiversidade, que seja socialmente justo, adequado e viável (CALDART et al., 2012) que vai na contramão da agricultura das monoculturas, das sementes transgênicas e dos de insumos químicos. Esta prática, portanto, ajuda a alicerçar um projeto de construção que articule a produção agrícola de base ecológica em agroecossistemas que possam interagir com o ambiente físico e químico de forma sadia e respeitosa, construindo uma base de conhecimentos para manejo sustentável que projete uma eficiência econômica e uma equidade social.

Assim, o pensamento decolonial fecunda uma aproximação de múltiplos saberes, sem a intenção de sobreposição ou conquista epistemológica, contribuindo de forma conceitual para um entendimento que subsidie diversos procedimentos na prática profissional, ressaltando, o manejo das sementes crioulas.

\section{Conservação das sementes crioulas}

Toda a diversidade genética que está sob contínuo manejo pelos camponeses, a partir de ciclos dinâmicos de cultivo e seleção dentro de seus respectivos e distintos agroecossistemas, apresenta centenas de milhares de variedades locais, que a depender do contexto são denominadas de variedades tradicionais, variedades locais e sementes crioulas. Independente da terminologia, dependente do ponto de vista político-ideológico, as sementes crioulas são uma afirmação da cultura e resistência da agricultura sustentável (SILVA, 2011), são o verdadeiro "patrimônio dos povos a serviço da humanidade".

As sementes de cultivares crioulos são mais do que uma unidade biológica, segundo Barcelos (2011), são um meio de propagação de vida e produto da evolução da natureza, que, além de fazer germinar plantas, cria um universo de saberes que se mantêm por milênios por meio da interação entre humanos e as demais espécies. A seleção natural, a que se remete Barcelos (2011), diz respeito à seleção das características e qualidades desejadas nas espécies vegetais pelos camponeses, com a intenção de propagar tais características em um processo constante de aperfeiçoamento autossustentado. Essas variedades selecionadas são aquelas de patrimônio genético e cultural dos povos tradicionais obtidos durante séculos, tanto por meio de evolução natural do melhoramento genético como também por meio do manejo sustentável ecologicamente inserido no ambiente e adaptado aos diversos ecossistemas.

Nesse sentido, o conhecimento sobre esse patrimônio genético associado à reprodução de saberes ocorre, a partir do lugar onde o camponês está inserido, devido à sua compreensão sobre o 
ambiente local, lembrando que, mais do que um produto, as sementes crioulas remetem a saberes tradicionais centenários que são ressignificados em função das trocas de conhecimento entre comunidades e regiões diferentes. Desse modo, concorda-se com Rossetto (2006, p. 15) quando afirma que “(...) cada indivíduo é portador de um sistema cultural em transformação constante, sendo estruturado pelos valores adquiridos no decorrer de sua trajetória pelos ensinamentos que recebem e pelas experiências vividas".

O termo reprodução de saberes, de acordo com Brumer e Anjos (2008), remete à perspectiva de continuidade dos indivíduos e designa preocupações e análises quanto à continuidade de estruturas, grupos, saberes, práticas e instruções sociais. Essa reprodução é importante para a sucessão de saberes e técnicas tradicionais que auxiliam os camponeses a não ficarem dependentes de empresas para executar sua produção. Diante disso, a introdução dos filhos no trabalho familiar, que ocorre desde cedo no âmbito rural, é uma prática de transmissão de saberes que objetiva, além da educação, um incentivo para a permanência no campo.

Nesse sentido, é possível afirmar que os saberes do camponês são fundamentados nas práticas cotidianas com o uso e manejo terra em junção com sua família, onde cada indivíduo apresenta um papel na unidade produtiva. Trata-se, assim, de um sistema de valores em que a vida do camponês vem a somar-se com a natureza e a direcionar suas práticas produtivas e sociais. Segundo Damasceno (1992) esse saber gestado nas práticas diárias, asseverando que o saber social é um saber gestado no cotidiano do trabalho e da luta camponesa, é a expressão concreta da consciência desse grupo social; um saber que é útil ao trabalho, aos enfrentamentos vividos cotidianamente pelos camponeses.

O conceito de saber social, quanto ao aspecto acima citado, aproxima-se da concepção de “saber cotidiano" de Agnes Heller (1987). Esse é entendido como o saber básico que os integrantes de um determinado grupo social necessitam para participar de seu ambiente, qualificando-se por ser prático (em termo técnico, político, religioso, etc.), mediante o qual o sujeito interfere na vida cotidiana. Dessa forma, o saber cotidiano refere-se a situações particulares, distinguindo-se do saber científico como apresenta Damasceno (1992, p. 48).

De acordo com Damasceno (1992), o saber social compreende os conhecimentos, as habilidades e os valores que são produzidos entre os camponeses em um determinado período. Logo, o saber social é um saber gestado no cotidiano do trabalho e útil para o trabalhador e seus enfrentamentos cotidianos. Assim, nas suas práticas produtivas, os camponeses utilizam-se de um "saber-fazer" que é visível nas formas como manuseiam as ferramentas de trabalho e no conhecimento que detêm acerca das condições locais de onde vivem. Tal aspecto evidencia a 
importância da família do camponês, pois é dentro desse núcleo que se dão as relações de produção e de reprodução do saber, já que todos os membros participam das atividades cotidianas.

Esse "saber” do camponês é de caráter empírico e se transfere de geração em geração por meio da ação e da prática das atividades produtivas, reproduzindo, também, o modo econômico em que este camponês está inserido. Assim, o modo econômico implica a escolha ou identificação de um sucessor e também é fundamental para a efetivação da sucessão. Segundo Carneiro (1998), a escolha pode não depender apenas da família ou dos fatores culturais, mas, também, do contexto socioeconômico em que se encontra a família.

Assim, as sementes crioulas e as práticas relacionadas a elas são de grande riqueza, tendo em vista que contribuem diretamente para a construção de técnicas de manejo, conservação da vida no planeta terra de forma sustentável e de reprodução de saberes. Nesse contexto, pode-se inferir que as sementes, de um modo geral, são muito mais que mercadoria, conforme destaca Barcelos (2011), pois consistem em recursos regenerativos que expressam a biodiversidade, constituindo, portanto, um patrimônio cultural na condição de bem imaterial.

Nessa ótica, as sementes crioulas não passam por modificações genéticas, como por exemplo, a transgenia, e recebem este nome porque historicamente foram manejadas por comunidades camponesas, indígenas denominadas como "tradicionais"12. Certos indivíduos, guardiões das sementes, desempenham funções primordiais no âmbito selecionado, pois fazem a preservação das sementes com o intuito de conservar e selecionar as espécies que não agridem o ambiente, mas sim, trabalhem de forma equilibrada em meios de mantença da história cultural, visto que são variedades desenvolvidas pelos camponeses e povos tradicionais.

Assim, para além de um código genético, estas sementes representam a cultura e o modo de viver destas comunidades (TRINDADE, 2006), e estão associadas também a práticas tradicionais de manejo dos agroecossistemas, uma vez que compõem o patrimônio da cultura rural regional brasileira, sendo que sua origem está vinculada à seleção dos exemplares mais aptos de cada espécie, priorizando um constante aprimoramento dos processos de manejo e plantio.

A manutenção desses recursos vegetais é fundamental para a sobrevivência da humanidade, fato esse garantido pelo importante papel em que os camponeses desempenham com as espécies agrícolas, o que garante uma ampla diversidade de sementes e plantas cultivadas. A conservação

\footnotetext{
${ }^{12}$ A partir deste entendimento, abordando a questão sob uma ótica decolonial, pode-se conceituar o conhecimento tradicional "como o conjunto de saberes e saber-fazer a respeito do mundo natural e sobrenatural, transmitido oralmente, de geração em geração. Para muitas dessas sociedades, sobretudo para as indígenas, há uma interligação orgânica entre o mundo natural, o sobrenatural e a organização social. Para tais comunidades, não há uma classificação dualista, uma linha divisória rígida entre o "natural" e o "social", mas sim um continuum entre ambos (DIEGUES et al., 2001, p. 31)".
} 
desses recursos genéticos caracteriza-se nas estratégias de conservação in situ/on farm (em habitats naturais) e ex situ (fora dos habitats naturais). A conservação ex situ de recursos genéticos de plantas ocorre por meio de bancos genéticos, nos quais se armazenam amostras de sementes ou de outros materiais reprodutivos de plantas, principalmente, sob condições controladas de temperatura e umidade (COSTA, 2013).

Segundo a Organização das Nações Unidas para Agricultura e Alimentação (FAO), no Tratado Internacional sobre Recursos Fitogenéticos para Alimentação e Agricultura (TIRFAA), assinado pelo Brasil em 2002, define-se a conservação in situ “(...) como a conservação dos ecossistemas e habitats naturais e a manutenção e a recuperação de populações viáveis de espécies em seus ambientes naturais e, no caso de espécies vegetais cultivadas ou domesticadas, no ambiente em que desenvolveram suas propriedades características" (BRASIL, 2008).

Derivada da conservação in situ, a conservação on farm (na roça) é definida como o “(...) manejo sustentável da diversidade genética de variedades agrícolas tradicionais localmente desenvolvidas, associadas a formas e parentes selvagens e desenvolvidas por agricultores dentro de um sistema de cultivo agrícola, hortícola ou agroflorestal tradicional (CLEMENT et al., 2007).

Além destas, as formas de manter e conservar as sementes são apresentadas de várias maneiras, como exemplo, as feiras de sementes, pode-se destacar como uma eficiente estratégia de conservação (in situ/on farm) e troca das espécies vegetais. Os bancos locais de sementes constituem uma estratégia segura para a conservação das variedades locais em uma determinada comunidade ou região. Os bancos representam segurança para os camponeses que estão sujeitos a condições de estresses ambientais como seca, inundações, ataques de insetos, pássaros em virtude dos desequilíbrios ambientais existentes, contaminações pelo fluxo gênico, além de outros fatores nos quais podem ocorrer uma forte e rápida erosão genética em seus recursos representados por inúmeras variedades locais (COSTA, 2013).

Em um banco local de sementes são colecionados o germoplasma ${ }^{13}$ de cultivos locais com importantes informações e conhecimentos associados, armazenando, regenerando ou multiplicando segundo as demandas. É uma prática inovadora que conserva as sementes locais e fornece às comunidades de camponeses a continuidade dos processos evolutivos locais e segurança alimentar (COSTA, 2013).

A sociedade e as comunidades tradicionais (que compreendem os povos indígenas, quilombolas, afrodescendentes, sertanejos, caiçaras, caboclos, extrativistas etc.) e, por fim, o

\footnotetext{
${ }^{13}$ Germoplasma pode ser definido como o conjunto de genótipos de uma espécie, ou seja, é a fonte de variabilidade genética disponível para o melhoramento de plantas (BESPALHOK et al., 2007).
} 
campesinato em toda a sua sociodiversidade, caracterizam-se por sua dependência em relação aos recursos naturais (NODARI; GUERRA, 2015). Por essa relação direta, essas populações (tradicionais e campesinato) destacam-se pelo seu importante papel na conservação de uma ampla diversidade de recursos genéticos vegetais, sendo considerados os verdadeiros "guardiões da diversidade" e um dos principais atores na prática da conservação on farm realizada diretamente em suas roças.

Nessa ótica, a conservação e a produção das sementes crioulas representa uma das fontes de segurança de sustentabilidade alimentar daquele que a cultiva, buscando assegurar o futuro e a valorização dos saberes empíricos. Por sua variedade combinada às boas qualidades nutricionais, se encontram bem adaptadas às condições locais e necessitam de baixa quantidade de insumos químicos agrícolas quando comparados com variedades submetidas a melhoramento genético (DAVIS, 2009), oferecendo, assim, grande capacidade de armazenamento para posterior reutilização.

As sementes crioulas, portanto, apresentam uma integridade genética e são reconhecidas morfologicamente pelos camponeses que as cultivam. Comumente as variedades são nomeadas e diferem entre si em relação à adaptação aos diferentes tipos de solo, ao período de cultivo, ao ciclo, estrutura morfológica e outras características. O importante é a ampla base genética conferida a estas sementes (HARLAN, 1971), que visam à valorização das identidades cultural e regional, além do aumento da agrobiodiversidade local, muitas vezes marginalizada por políticas públicas ${ }^{14}$ dissociadas da realidade brasileira.

Estas características peculiares às sementes crioulas conferem a elas uma adaptabilidade genética às condições edafoclimáticas, uma vez que são cultivadas há anos sob as mesmas condições de solo e clima, da mesma forma que apresentam uma adaptabilidade sociocultural, a partir do momento que estão diretamente ligadas ao conhecimento local em torno do uso e conservação destas sementes. Sua utilização promove a conservação dos saberes locais e, consequentemente, sua aquisição denota um resgate de processos sociais em prol da agrobiodiversidade regional. Estas medidas contribuem para a autonomia do campesinato, por intermédio de uma matriz que orienta a redução de insumos externos em prol de um diálogo para com a natureza.

Este diferencial, por sua vez, se demonstra como “(...) outra matriz tecnológica pautada na produção de alimentos limpos, saudáveis, sem agrotóxicos, que respeita os diversos modos de vida das populações do campo, fortalecendo a cultura alimentar de cada região e a manutenção da

\footnotetext{
${ }^{14}$ Neste contexto, pode-se salientar o Programa de Aquisição de Alimentos (PAA), uma ação do governo federal, que proporciona ao agricultor familiar vender seus alimentos oriundos de sementes crioulas. Neste, o Estado adquire produtos agroecológicos e destinam a quem precisa, como forma de incentivo à produção orgânica. O PAA dispensa processo licitatório e seleciona sujeitos que se enquadram em situações de insegurança alimentar e nutricional, bem como aqueles atendidos por programas assistenciais (BRASIL, 1996).
} 
sociobiodiversidade" (MOREIRA et al., 2010, p. 210). Explicitando uma diversidade produtiva e alimentar, as sementes crioulas são pautadas no respeito ao ambiente e à cultura local, de modo a fortalecer os movimentos regionais, independente das atividades hegemônicas e predatórias. $\mathrm{O}$ ato do cultivo, portanto, se torna uma manifestação de conservação do patrimônio sociocultural, sob um aspecto multidimensional.

Por intermédio das sementes crioulas, levando em consideração o ato de conservar a agrobioversidade, o risco de perda de todo o plantio é menor do que as sementes geneticamente iguais. Por este motivo, apresentam maior resistência às variações climáticas e denotam maior capacidade reprodutiva. Diante disto, seu resgate e distribuição entre camponeses fundamenta-se na garantia da reprodução da vida e da cultura regional (BARBOSA et al., 2010).

Desta forma, far-se-á necessário manter os movimentos de valorização das sementes crioulas como intenção de conservar a biodiversidade regional, do fortalecimento do campesinato e da materialização das ações decoloniais garantidoras de uma múltipla realidade agroecológica.

\section{Conclusões}

A prática de resgate e conservação das sementes crioulas pelos guardiões busca o desprendimento das relações impostas pelo sistema capitalista de produção e afirma a busca de uma relação respeitosa com a natureza. Evidencia-se, além disso, a aprendizagem com a natureza por parte daqueles que cultivam a terra, guardando seus saberes. Tal aprendizagem também se expressa em uma relação de responsabilidade com o ambiente e seus recursos, garantindo a sustentabilidade da biodiversidade local bem como na troca de saberes e na valorização cultural.

Na mesma linha, o aporte decolonial se fez pertinente e pertencente ao debate, uma vez que propicia a revisão de um conjunto de práticas representativas e discursos que comunicam as atividades regionais e as diferentes percepções de mundo, para além de um pensamento hegemônico neste tocante. Ainda, possibilitou reconectar as evidências materiais do manejo das sementes crioulas como uma proposta decolonial que repensa as interrelações entre o homem e a natureza, bem como oferece passos significativos para alicerçar a sustentabilidade, o desenvolvimento e os saberes originários.

Por sua vez, a conservação das sementes crioulas, considerada como um processo de construção de autonomia, já que o camponês guarda suas sementes e não depende dos pacotes tecnológicos, interfere diretamente em sua renda. Ressalta-se, no entanto, a necessidade de estudos 
voltados para a valorização das sementes crioulas, com o objetivo de manter os saberes locais ligados às técnicas de conservação, manejo e produção.

Por fim, torna-se evidente nesse estudo que são os conhecimentos atrelados às práticas de produção que os guardiões conservam. Essa tradição, fortemente marcada por valores simbólicos, busca a manutenção da vida e do ambiente. E, para que tais saberes e práticas se perpetuem, necessitase da elaboração de projetos e políticas públicas de incentivo a esses modos de produção, bem como que a comunidade científica reconheça o esforço dos camponeses. Assim, será possível garantir a manutenção desses saberes.

\section{Referências}

ALTIERI, M. A. Agroecologia: a dinâmica produtiva da agricultura sustentável. 3. ed. Porto Alegre: UFRGS, 2001, 110p.

ALTIERI, M. A. Agroecologia: bases científicas para uma agricultura sustentável. Guaíba: Agropecuária, 2002, 592p.

ALTIERI, M. A. El "estado del arte" de la agroecología y su contribución al desarrollo rural em América Latina. In: CADENAS MARÍN, A. (Ed.). Agricultura y desarrollo sostenible. Madrid: MAPA, 1995. 151-203p.

ALTIERI, M. A. Por qué estudiar la agricultura tradicional? In: GONZÁLEZ ALCANTUD, J. A.; GONZÁLEZ DE MOLINA, M. (Ed.). La tierra: mitos, ritos y realidades. Barcelona: Anthopos, 1992. 332-350 p.

ALTIERI, M. A. Sustainable agriculture. In: Encyclopedia of Agricultural Science. Berkeley: Academic Press, 1994. 239-247p.

ALTIREI M. A. Agroecologia: a dinâmica produtiva da agricultura sustentável. $4^{\circ}$ ed. Porto Alegre: Editora da UFRGS, 2004, 120p.

AMORIM, L. O. Plantando semente crioula, colhendo agroecologia: agrobiodiversidade e campesinato no Alto Sertão Sergipano. 2016. Dissertação. 140f. (Mestrado em Desenvolvimento e Meio Ambiente), Universidade Federal de Pernambuco, Recife, 2016.

BARBOSA, F. R. S.; RIBEIRO, G. G.; DIAS, M. S.; ASSUNÇÃO, H. F.; RIBEIRO, D. D. Banco de sementes: autonomia para o pequeno produtor do sudoeste goiano. Cadernos de Agroecologia, Porto Alegre, v. 5 n.1, p. 1-4, 2010.

BARCELOS, J. R. O. A Tutela Jurídica das Sementes: a proteção da diversidade e da integridade do patrimônio genético e cultural brasileiro à luz do princípio da proibição de retrocesso ambiental. Porto Alegre: Verbo Jurídico, 2011. 176p. 
BESPALHOK, J. A.; GUERRA, E. P.; OLIVEIRA, R. Uso e conservação do germoplasma. Melhoramento de plantas. Disponível em: <http://www.bespa.agrarias.ufpr.br/paginas/livro/capitulo\%203.pdf>. Acesso em 20 de Julho de 2018.

BEVILAQUA, G. A. P.; ANTUNES, I. F. BARBIERI, R. L.; SCHWENGBER, J. E.; SILVA, S. D. A.; LEITE, D. L.; CARDOSO, J. H. Agricultores guardiões de sementes e ampliação da agrobiodiversidade. Cadernos de Ciência \& Tecnologia, Brasília, v. 31, n. 1, p. 99-118, 2014.

BEVILAQUA, G. A. P.; BEVILAQUIA, D.; BEVILAQUIA, E.; ROSA, I. F. A.; SILCA, S. D. A. Desenvolvimento in situ de cultivares crioulas através de agricultores guardiões de sementes. Revista Brasileira de Agroecologia, Porto Alegre, v. 4, n. 2, p. 1273-1275, 2009.

BRASIL. Decreto no 1946 de junho de 1996. Programa Nacional de Fortalecimento da Agricultura Familiar. Disponível em: www.pronaf.gov.br. Acesso em 20 de julho de 2018.

BRASIL. Lei $\mathbf{n}^{\mathbf{0}} \mathbf{1 0 . 7 1 1}$ de 05 de agosto de 2003. Disponível em: http://www.planalto.gov.br/ccivil_03/Leis/2003/L10.711.htm. Acesso em: 24 de maio de 2018.

BRASIL. Ministério da Agricultura, Pecuária e Abastecimento. Tratado Internacional sobre Recursos Fitogenéticos para Alimentação e Agricultura. Brasília. 2008. Disponível em: <http://www.planalto.gov.br/ccivil_03/_Ato2007-2010/2008/Decreto/D6476.htm>. Acesso em: 20 de Julho de 2018.

BRASIL. Plano Nacional de Agroecologia e Produção Orgânica - PLANAPO. Brasília: MDS; Ciapo, 2013. Disponível em: http://www.mda.gov.br/planapo/. Acesso em: 13 de Out de 2018.

BRUMER, A.; ANJOS, G. Gênero e reprodução social na agricultura familiar. Revista NERA, Presidente Prudente, v. 11, n. 12. p. 6-17, 2008.

BUENAVENTURA, E. E. J. Expertos culturales e intervención social: tensiones y transformaciones en antropologia aplicada. Revista CS, Cali, v. 1, n. 2, p. 265-285, 2008.

CALDART, R. S.; PEREIRA, I. B.; ALENTEJANO, P.; FRIGOTTO, G. Dicionário da Educação do Campo. São Paulo: Escola Politécnica de Saúde Joaquim Venâncio, Expressão Popular, 2012, $788 \mathrm{p}$.

CAPORAL, F. R.; COSTABEBER, J. A. Agroecologia e desenvolvimento rural sustentável: perspectivas para uma nova extensão rural. Agroecologia e Desenvolvimento Rural Sustentável, Porto Alegre, v. 1, n. 1, p. 16-37, 2000a.

CAPORAL, F. R.; COSTABEBER, J. A. Agroecologia e desenvolvimento rural sustentável: perspectivas para uma nova extensão rural. In: ETGES, V. E. (org.). Desenvolvimento rural: potencialidades em questão. Santa Cruz do Sul: EDUSC, 2001. 19-52p.

CAPORAL, F. R.; COSTABEBER, J. A. Agroecologia e sustentabilidade: base conceptual para uma nova extensão rural. In: WORLD CONGRESS OF RURAL SOCIOLOGY, 2000, Rio de Janeiro: IRSA, 2000b. 
CAPORAL, F. R.; COSTABEBER, J. A. Análise multidimensional da sustentabilidade: uma proposta metodológica a partir da Agroecologia. Agroecologia e Desenvolvimento Rural Sustentável, Porto Alegre, v. 3, n. 3, p. 70-85, 2002.

CARNEIRO, M. J. Camponeses agricultores e pluriatividade. Rio de Janeiro: Contra Capa Livraria, 1998, 228p.

CARVALHO, H. M. O campesinato contemporâneo como modo de produção e como classe social. Curitiba, 2012. Disponível no site: 〈http:www.mcpbrasil.org.br〉. Acesso em 10/07/2018.

CASTRO-GÓMEZ, S. Ciências sociais, violência epistêmica e o problema da "invenção do outro". In: LANDER, E. (Org.). A colonialidade do saber: eurocentrismo e ciências sociais, perspectivas latino-americanas. Buenos Aires: CLACSO, 2005. 80-87p.

CHOAY, F. A Alegoria do Patrimônio. São Paulo: Estação Liberdade. 2001, 282p.

CLEMENT, C. R.; ROCHA, S. F. R; COLE, D. M.; VIVIAN, J. L. Conservação on farm. In: NASS, L. L. Recursos genéticos vegetais. Brasília, DF: Embrapa Recursos Genéticos e Biotecnologia, 2007. 511-543p.

COLAÇO, T. L. Novas perspectivas para a antropologia jurídica na América Latina: o direito e o pensamento decolonial. Florianópolis: Fundação Boiteaux, 2012, 227p.

COSTA, F. M. Diversidade genética e distribuição geográfica: uma abordagem para a conservação on farm e ex situ e o uso sustentável dos recursos genéticos de milho do Oeste de Santa Catarina. 2013. Dissertação. 211f. (Mestrado em Recursos Genéticos Vegetais). Universidade Federal de Santa Catarina. Florianópolis, Santa Catarina. 2013.

CUNHA, B. P.; AUGUSTIN, S.; LIMA, L. G. D.; COSTA, N. R. A. Os Saberes ambientais, sustentabilidade e olhar jurídico: visitando a obra de Enrique Leff. Caxias do Sul: Universidade de Caxias do Sul, 2015. 309p.

DAMASCENO, M. N. A construção do saber social pelo camponês na sua prática produtiva e política. In: Sociedade civil e educação, Campinas (SP): Ande/Papirus/Andep, Cedes, 1992, 35-55p.

DAVIS, R. D. Declining Fruit and Vegetable Nutrient Composition: What Is the Evidence? HortScience, Virgínia, EUA, v. 44, n. 1, p. 15-19, 2009.

DE MASI, D. Criatividade e grupos criativos. Rio de Janeiro: Sextante, 2003. 795p.

DENARDI, R. A. Agricultura familiar e políticas públicas: alguns dilemas e desafios para o desenvolvimento rural sustentável. Agroecologia e Desenvolvimento Rural Sustentável, Porto Alegre, v. 2, n. 3, p. 56-62, 2001.

DIEGUES, A. C.; ARRUDA, R. S. V.; SILVA, V. C. F.; ANDRADE, D. Saberes Tradicionais e Biodiversidade no Brasil. São Paulo: USP, 2001, 190p.

DOMingueZ, O. C.; PESKE, S. T.; VILlELA, F. A.; BAUDET, L. Sistema informal de sementes: causas, consequências e alternativas. Pelotas: Editora Universitária/UFPel, 2000. 207p. 
DUSSEL, E. Europa, modernidade e eurocentrismo. In: LANDER, E. (Org.). A colonialidade do saber: eurocentrismo e ciências sociais, perspectivas latino-americanas. Buenos Aires: CLACSO, 2005. 24-32p.

FLORIANI, D.; KNECHTEL, M. R. Educação ambiental: epistemologia e metodologia. Curitiba: Vicentina, 2003, 143p.

FOUCAULT, M. Microfísica do poder. 29 ed. Tradução de Roberto Machado. Rio de Janeiro: Graal, 2011. 174p.

GALEANO, E. As veias abertas da América Latina. 15 ed. Tradução de Galeano Freitas. Rio de Janeiro: Paz e Terra, 1983, 201p.

GLIESSMAN, S. R. Agroecologia: processos ecológicos em Agricultura Sustentável. 3ed. Porto Alegre: Ed. UFRGS, 2007, 653p.

GROSFOGUEL, R.; MIGNOLO, W. Intervenciones decoloniales: una breve introducción. Revista Tabula Rasa, v. 1, n. 9, p. 29-37, 2008.

GUZMÁN CASADO, G.; MOLINA, M. G.; GUZMAN, E. S. Introducción a la Agroecología como desarrollo rural sostenible. Madrid: EdicionesMundi-Prensa, 2000. 196p.

GUZMÁN, E. S.; OTTMANN, G. Las dimensiones de la Agroecología. In: Instituto de sociología y estudios campesinos. Manual de olivicultura ecológica. Córdoba: Universidad de Córdoba, 2004. $11-26 p$.

HARLAN, J. R. Agricultural Origins: centers and noncenters. Science, Estados Unidos, n. 1, v. 174, p. 468-474, 1971.

HELLER, A. Sociología de la vida cotidiana. 2 Sociología de la vida cotidiana ed. Barcelona: Península, 1987, 420p.

JARVIS, D. I.; MYER, L.; KLEMICK, H.; QUARINO, L.; SMALE, M.; BROWN A. H. D.; SADIKI, M.; STHAPIT, B.; HODGKIN, T. A training guide for in-situ conservation on-farm. Version 1. Rome/Italy: IPGRI, 2000, 56p.

LEFF, E. Agroecologia e saber ambiental. Agroecologia e Desenvolvimento Rural, Porto Alegre, v. 3, n. 1, p. 36-51, 2002.

LEFF, E. Pobreza, Gestion participativa de los recursos naturales en las comunidades rurales: una vision desde américa latina. Revista Latinoamericana de Economia, México, v. 26, n. 100, p. 223240, 1995.

LEFF, E. Saber ambiental: sustentabilidade, racionalidade, complexidade e poder. Tradução de Lúcia Mathilde Endlich Orth. 9 ed. Petrópolis: RJ: Vozes, 2012, 494p. 
LIMA ANDRADE, J. R. Uma estratégia alternativa de desenvolvimento regional: o turismo no estado de Sergipe. In: OLIVEIRA, G. B.; SOUZA-LIMA, J. E. (orgs.) O desenvolvimento sustentável em foco - uma contribuição multidisciplinar. Curitiba/São Paulo: Annablume, 2006. 19-25p.

MARTÍNEZ ALIER, J. Ecologismo de los Pobres. Barcelona, España. Editroa Icaria, 2009, 395p.

MARTINS, P. H. O ensaio sobre o dom de Marcel Mauss: um texto pioneiro da crítica decolonial. Sociologias, Porto Alegre, v. 16, n. 36, p. 22-41, 2014.

MOREIRA, C. O Programa de Aquisição de Alimentos da Agricultura familiar e o fome Zero. In: ARANHA, A. V. Fome Zero: uma história brasileira. v. II. Brasília, DF. 2010. 206-218p.

NODARI, R. O.; GUERRA, M. P. A agroecologia: estratégias de pesquisa e valores. Ciência, Valores e Alternativas. Estudos Avançados, São Paulo, v. 29, n. 83, p. 183-207. 2015.

NORGAARD, R. B. A base epistemológica da agroecologia. In: ALTIERI, M. A. (Ed.). Agroecologia: as bases científicas da agricultura alternativa. Rio de Janeiro: PTA: FASE, 1989. 4248p.

OLIVEIRA, G. B. O. Uma discussão sobre o conceito de desenvolvimento. Revista FAE, Curitiba, v. 5, n. 2, p. 37-48, 2002.

PELWING, A. B.; FRANK, L. B.; BARROS, B. Sementes crioulas: o estado da arte no Rio Grande do Sul. Revista de Economia e Sociologia Rural, Brasília, v. 46, n. 2, p. 2008.

PETERSEN, P.; DAL SOGLIO, F. K.; CAPORAL, F. R. A construção de uma ciência a serviço do campesinato. In: PETERSEN, Paulo (Ed.); Agricultura Familiar Camponesa na Construção do Futuro. Rio de Janeiro: ASPTA, 2009. 85-103p.

PINHEIRO, S.; NASR, N. Y.; LUZ, D. A agricultura ecológica e a máfia dos agrotóxicos no Brasil. Porto Alegre: Edição dos Autores, 2000. 356p.

PORTANOVA, R.; CORTE, T. D. Descolonização e luta socioambiental: o paradigma dos saberes do sul. In: CUNHA, B. P.; AUGUSTIN, S.; LIMA, L. G. D.; COSTA, N. R. A. (orgs.) Os saberes ambientais, sustentabilidade e olhar jurídico: visitando a obra de Enrique Leff. Caixias do Sul: Educs, 2015. 125-145p.

QUIJANO, A. Colonialidade do poder, eurocentrismo e América Latina. In: LANDER, E. (org.) A Colonialidade do saber: eurocentrismo e ciências sociais. Buenos Aires: Clacso, 2005. 107-130p.

RAVEN, P. H.; EVERT, R. F.; EICHHORN, S. E. Biologia Vegetal. Tradução Ana Claudia de Macêdo, Rio de Janeiro: Guanabara, 2007, 906p.

ROSSETO, O. C. Cultura, Sustentabilidade ambiental: desvelando caminhos teóricos. Revista Matogrossense de Geografia, Cuiabá, v. 11, n. 9, p. 9-28, 2006.

SACHS, I. Estratégias de transição para o século XXI: desenvolvimento e meio ambiente. São Paulo: Studio Nobel, 1994. 103p. 
SANTOS, M. T. L. F. A Economia Perversa: o impacto dos mercados sobre o meio ambiente. Prim@ Facie, João Pessoa, v 5, n. 9, p. 106-125, 2006.

SHIVA, V. Monoculturas da mente: perspectivas da biodiversidade e da biotecnologia. Tradução de Dinah de Abreu Azevedo. São Paulo: Gaia, 2003, 240p.

SILVA, N. C. A. Manejo da diversidade genética de milho como estratégia para a conservação agrobiodiversidade no norte de Minas Gerais. 2011. 136f. Dissertação (Mestrado em Ciências Agrárias). Instituto de Ciências Agrárias, Universidade Federal de Minas Gerais. Montes Claros/MG, 2011.

TOSCANO, L. F. Agricultura familiar e seu grande desafio. Diário de Votuporanga, Ano 50, ${ }^{\circ}$ 12.769, 09 de Outubro de 2003, p. 02. Disponível em: http://www.feis.unesp.br/irrigacao/dv09102003.htm. Acesso em: 10 de Dez de 2018.

TRINDADE, C. C. Sementes crioulas e transgênicos. Uma reflexão sobresua relação com as comunidades tradicionais. In: CONGRESSO NACIONAL DO CONPEDI, XV, Manaus. Conpedi, 2006. 1-15p.

VIGLIZZO, E. F. La trampa de Malthus: agricultura, competitividad y medio ambiente en el siglo XXI. Buenos Aires: Universitaria de Buenos Aires, 2001, 180p.

Artigo recebido em 11/12/2018. Aceito para publicação em 27/05/2019. 